Recibido: 13-diciembre-2013

Aceptado: 21-diciembre-2013

\title{
LOS PÁRAMOS ECUATORIANOS: CARACTERIZACIÓN Y CONSIDERACIONES PARA SU CONSERVACIÓN Y APROVECHAMIENTO SOSTENIBLE
}

MIGUEL CAMACHO

Facultad de Medicina Veterinaria y Zootecnia Universidad Central del Ecuador 


\section{RESUMEN}

En este trabajo se proponen elementos para una política alternativa hacia la conservación y aprovechamiento sostenible de los páramos. Como también, iniciativas de manejo y conservación de los mismos. El papel que debe cumplir el Estado frente a los páramos y el páramo como naturaleza y entorno cultural.

Palabras clave: páramo, naturaleza, cultura, Estado, política, alternativa.

\section{ABSTRACT}

In this paper elements of a political alternative to the conservation and sustainable use of the moors are proposed. As well, management initiatives and conservation thereof. The paper must meet the state against the moors and moor as nature and cultural environment.

Keywords: páramo, nature, culture, State, politics, alternative, moor. 


\section{Introducción}

En el documento se hace una conceptualización de los páramos en el Ecuador en sus dimensiones de ecosistema y paisaje cultural. Se aborda lo que ha sido su manejo y aprovechamiento tradicional sea en actividades agroproductivas, pecuarias y forestales, y el análisis histórico de las políticas agrarias a partir de los años sesenta y la influencia de ellas en la situación actual del páramo. Este análisis deja traslucir la importancia del páramo como bien ambiental y las funciones que desempeña. $Y$ sobre estos contenidos se analiza las iniciativas para el manejo y conservación de páramos y la actuación del Estado ecuatoriano frente a los páramos y se plantea los elementos de una política alternativa para la conservación y aprovechamiento sostenible de los páramos ecuatorianos.

\section{Los páramos ecuatorianos}

En América Latina la alta montaña es un paisaje que integra: el piso glaciar de las cúspides de los nevados y de los volcanes de gran altura de la Cordillera de los Andes. Por debajo de él se ubica una franja periglaciar, casi desértica, conocida como arenal hacia donde, lentamente, van ascendiendo las especies más resistentes de los páramos. Los páramos. Y el bosque andino y/o relicto de vegetación arbustiva que en otros tiempos debió ser parte de verdaderas selvas andinas.

\subsection{El páramo como ecosistema}

El páramo es un ecosistema de altura inmerso en un espacio geo social mayor, conocido como la alta montaña ecuatorial, donde coexiste con otros sistemas de altura. Es una formación ecológica específica de los Andes septentrionales (Colombia y Venezuela) que se localiza entre las cotas de los 3.200 y los 4.700 msnm (metros sobre el nivel del mar). Los Andes del sur, en tanto, forman la puna. ${ }^{1}$ Los dos son formaciones herbáceas de altura pero se diferencian porque el páramo recibe más precipitaciones (lluvia y/o neblina), por la alta humedad relativa ( $60 \%$ ante $30 \%$ ), y el tapiz vegetal que lo constituye es más tupido que el de la puna.

El Ecuador ocupa una posición geográfica intermedia entre estos polos y sus praderas naturales de altura hacen transición entre ambos tipos. En el norte del país se encuentra el límite sur del páramo con frailejón (Espeletia) que es una formación vegetal muy extensa en Colombia y Venezuela; en los valles de Sumbahua y Palmira, condiciones edáficas (suelos sobre material pedregoso fluvio glacial o sobre piedra pómez) y condiciones climáticas (llanuras en posición de "sotavento") hacen que la pradera de Stipa ichu, esparcida en matas diseminadas, se asemeje a la puna (CESA, 1983, p. 74).

El páramo en el país se ubica entre las cotas de los 3.200 y los 4.700 msnm (límite inferior del piso glaciar o gélido). La mayoría de los páramos ecuatorianos son húmedos. Sobre ellos caen entre 500 y 2.000 mm de precipitación anual (lo cual genera impactos sobre el crecimiento de la vegetación natural y pasturas). Por lo general la cordillera Central $^{2}$ recibe más lluvias que la Occidental.

\footnotetext{
${ }^{1}$ Puna es un área de herbáceas en altitudes entre 3.600 y 5.200 msnm localizada en los Andes del sur (Perú, Bolivia y norte de Argentina).

2 Los Andes meridionales, conformados por los ramales de la cordillera del sur en las jurisdicciones de las provincias de Cañar, Azuay y Loja, son geológicamente más antiguos y más bajos que la cordillera Occidental y Central del centro y del norte del Ecuador -provincias de Carchi, Imbabura, Pichincha, Tungurahua,
} 
En conjunto constituyen "verdaderas esponjas de agua, gracias a la gran capacidad de retención de agua de sus suelos, que supera el 200\% de su propio peso seco" (Cañadas, 1983, p. 96). Sólo unas pequeñas áreas secas y ecológicamente similares a la puna, (250 a $500 \mathrm{~mm}$ de precipitación anual) se encuentran en el Ecuador: el arenal del Chimborazo, las alturas del Illiniza, y la meseta de Palmira. Por su alta humedad, los páramos del Ecuador son más similares a los de Colombia, Venezuela y Costa Rica, que a las punas de los Andes Centrales y del Sur. Fuera de América Central y Latinoamérica (Hess, s/f, p. 68), la ecozona paramal es solamente comparable con la de las montañas altas de África del este y Nueva Guinea.

Debido a las condiciones climáticas indicadas, las diferencias fitosociológicas entre las punas del sur y los páramos de los andes norteños, son significativas. La vegetación de la puna es xerófila, y dispersa. En cambio el páramo ecuatoriano está constituido por una vegetación natural herbácea de carácter permanente conformada mayoritariamente por gramíneas como la paja (Stipa ichu) -debido a lo cual deriva su denominación común de "pajonal"-, festuca y calamagrostis; otras formas de vida vegetal "arosetada" y en "almohadilla" son típicas y aparecen como adaptaciones a la altura, y adoptan funciones de almacenamiento de agua en grandes cantidades -el musgo del género Sphagnum (Vargas y Rivera, 1991, p. 46) es un reservorio capaz de retener en sus tejidos hasta 40 veces su peso seco con agua-. Son frecuentes también especies arbustivas $y$ leñosas, con relictos de bosques nativos. Es

Chimborazo y Bolívar- y se diferencia en varios aspectos físicos como: humedad, régimen de lluvias, suelo, etc. una vegetación de baja biomasa, con descomposición lenta de la materia orgánica y acumulación de necromasa en pie y en el suelo; adaptadas para resistir las bajas temperaturas y la alta radiación ultravioleta del medio (pero no las quemas anuales, que se analizan más adelante).

Los páramos del Ecuador no son homogéneos. Factores diversificantes sobre la vegetación paramal son tanto los suelos, como los factores meteorológicos (temperatura, precipitación, evapotranspiración, y los vientos), los cuales producen una gran gama de microclimas $y$ zonas de vida. Por ejemplo, la temperatura promedio anual a $3.600 \mathrm{msnm}$, corresponde en la cordillera Occidental a $9.32{ }^{\circ} \mathrm{C}$, y en la Central a $8.32{ }^{\circ} \mathrm{C}$, lo cual significa, que a la misma altura la cordillera Central es un grado más fría que la Occidental. Esto, por cierto, tiene sus efectos sobre la vegetación natural y cultivada.

Según ello el páramo encierra diversas categorías; un factor de diferenciación es la altura. Acosta Solís (1984) diferencia en él, tres categorías:

- Páramo inferior, zona de pajonal entre 3.200 y 4.000 msnm, con una tendencia a subir del límite inferior por intervención de la presión humana.

- $\quad$ Páramo medio, entre 4.000 y 4.500 msnm.

- $\quad$ Páramo superior sobre los 4.500 msnm.

Entre éstas tienen más importancia los pisos inferior y medio.

Cañadas, op. cit., en tanto, considera al páramo como un "continuun biológico"; no obstante, por los factores de diferenciación enunciados, al cruzar la altura con la 
precipitación y la temperatura media anual, se crean diferentes microclimas $y$ formaciones ecológicas; $y$, en base al sistema de Holdridge, divide al páramo en dos pisos altitudinales: subpáramos y páramos.

Los subpáramos se ubican entre 3.000 a $3.600 \mathrm{msnm}$ en la cordillera Central y entre 3.200 a 3.900 msnm en la cordillera Occidental, con un rango de temperaturas entre 6 y $12^{\circ} \mathrm{C}$

Los páramos, en cambio, representan la zona sobre los 3.600 o $3.900 \mathrm{msnm}$, respectivamente, hasta los $4.700 \mathrm{msnm}$, con temperaturas entre 3 y $6{ }^{\circ} \mathrm{C}$. Los dos pisos altitudinales se dividen en siete formaciones ecológicas, que se diferencian por el nivel de precipitación anual; estas características y el espacio territorial que ocupan, se aprecian a continuación:

$\begin{array}{lllr}\text { - } & \text { Bosque húmedo subalpino } & 250 \text { a } 500 \mathrm{~mm} & 25.800 \mathrm{ha} \\ \text { - Bosque muy húmedo subalpino } & 500 \text { a } 1000 \mathrm{~mm} & 207.950 \mathrm{ha} \\ \text { - Sosque pluvial subalpino } & 1000 \text { a } 2000 \mathrm{~mm} & 213.125 \mathrm{ha} \\ \text { - Subpáramo seco } & 250 \text { a } 500 \mathrm{~mm} & 110.225 \mathrm{ha} \\ \text { - Subpáramo húmedo } & 500 \text { a } 1000 \mathrm{~mm} & 974.575 \mathrm{ha} \\ \text { - Subpáramo muy húmedo } & 1000 \text { a } 2000 \mathrm{~mm} & 1^{\prime} 098.045 \mathrm{ha} \\ \text { - Subpáramo lluvioso } & >2000 \mathrm{~mm} & 104.675 \mathrm{ha}\end{array}$

Es decir los páramos en el país, según Cañadas, ocupan el 9,6\% de su territorio y las jurisdicciones de 15 provincias.

Los páramos son utilizados por una rica fauna silvestre -osos, venados, aves, ranas, lagartijas e insectos- para los que constituye un hábitat único.

Este gran territorio, alberga numerosas de las áreas protegidas del país, como se aprecia más adelante.

\subsection{El páramo como paisaje cultural}

El páramo como ecosistema encierra gran biodiversidad, es fuente de recursos naturales, desempeña importantes funciones ambientales, pero al mismo tiene una his- toria de relaciones, mutuamente determinantes, de la naturaleza con los pueblos asentados en esos territorios o cerca de ellos.

Esta doble dimensión ha determinado que se lo catalogue como un ecosistema y un paisaje cultural. Su principal, aunque no única, función relacionada con las sociedades humanas es la capacidad de sus suelos especiales de captar, almacenar y distribuir agua a las tierras bajas, donde es usada por millones de personas, cerca y lejos del páramo, para riego, agua potable, generación hidroeléctrica, etc. El páramo también es el territorio y hogar de muchas comunidades campesinas e indígenas que han pasado por una historia antigua de marginación por parte de actores poderosos y que han hecho del páramo, de manera deliberada o forzada, su fuente de sustento.

Estas poblaciones han desarrollado, una cultura paramera que se manifiesta en la actualidad a través de procesos de empoderamiento, autodeterminación y recuperación. Esto les ha llevado a establecer relaciones, muchas veces conflictivas con actores "externos" al páramo como haciendas, ciudades e industrias que han visto el páramo, entre otras cosas, una fuente aparentemente infinita de agua. Muchas veces la relación profunda entre el valle y el páramo no ha sido siquiera reconocida.

Tanto o más que un ecosistema el páramo es un paisaje cultural (Román y otros, 2003, p. 96), dado que buena parte de páramo no es un ecosistema natural, sino el resultado de interacciones antiguas con la gente. El típico pajonal que está mayoritariamente en el imaginario de la gente y que en el Ecuador constituye el $60 \%$ del páramo, ha sido generado por las quemas y el pastoreo desde hace mucho tiempo. Si 
bien esto ha generado impactos, también ha establecido una cultura y una forma de vida que es parte del discurso y la práctica de las nacionalidades indígenas en cuanto a costumbres, territorialidad, soberanía e identidad histórica.

\subsection{Las prácticas agroproductivas en los páramos}

Entre las décadas de los sesena y ochenta del siglo XX, se produjeron cambios importantes en la estructura agraria, extremadamente concentrada en grandes unidades productivas, que llevan a procesos de Reforma Agraria encaminados a distribuir más equitativamente la tierra; así como a las concepciones de lo agrario.

Aparejada a la Reforma Agraria se considera como estrategia la ampliación de frontera agrícola para incrementar la disponibilidad de tierras para la producción. La legislación de reforma agraria incorporó ese enfoque y, según Gondard y Muzurek (2001, citados por Román y otros, 2013, p. 100) su aplicación derivó en una "amplia progresión de los cultivos hacia pisos altitudinales superiores".

Para ellos, esa expansión tuvo dos modalidades según la formación vegetal a expensas de la cual se produjo: cuando subsistía una franja de matorral o excepcionalmente de bosque siempre verde entre la zona agrícola y el páramo, se talaba esa formación leñosa, se instalaba un cultivo de papa para aprovechar la riqueza del nuevo suelo, y después se sembraba pasto o, se dejaba crecer el pasto natural; este proceso se desarrolló tanto al norte como al sur de los Andes. En cambio, en los Andes centrales del país, las actividades agropecuarias se expandieron directamente hacia el páramo, dado que ya no subsistían huellas de formaciones leñosas naturales, siendo además el medio más seco, la presión demográfica inmediata más fuerte y, la altitud local más elevada. En una primera etapa, se establece un sistema de cultivo papero, con rendimientos muy altos basados en la elevada productividad de los suelos recién cultivados; al bajar la producción y aumentar las plagas, se pasa paulatinamente al sistema tradicional de cultivo de altura: rotación de la papa con otros cultivos andinos como haba y cebada; incluye un tiempo de descanso o barbecho, mientras se restablece la fertilidad del suelo con el sistema de talanqueo nocturno del ganado.

Para Crissman (2003, citado por Román y otros, Ibid.) siempre se ha dado un uso agrícola de las zonas parameras, pero con el avance de la frontera agrícola hacia las zonas altas de los páramos, esa agricultura las pone en alto riesgo. "Por ser relativamente más arriesgada la agricultura de zonas altas, siempre tendrá problemas especiales y poca justificación ecológica, agrícola o económica de continuar en un futuro indefinido".

Con relación a la afirmación de que siempre se ha dado uso agrícola a las zonas parameras; por lo menos para el caso de las prácticas agroproductivas de las comunidades indígenas, se deberá considerar la estrategia del aprovechamiento complementario de distintos pisos ecológicos como práctica ancestral de las distintas culturas andinas y comprender la racionalidad campesino indígena de ocupación de los páramos.

También Crissman manifiesta que, por su naturaleza, la agricultura en tierras de páramo "causa la alteración del ambiente, en especial de la flora y la fauna y el recurso 
suelo. Las prácticas agropecuarias son culpables de la eliminación indiscriminada de los bosques nativos, el pastoreo persistente, la quema, el cultivo excesivo e incorrecto. Todas esas prácticas tienen impacto en el suelo en especial en la erosión del suelo".

Con respecto a la alteración de los suelos de páramo, no puede dejar de señalarse que el problema del desarrollo de una agricultura en las zonas de altura, se agrava por el alto impacto que produce la extracción y venta de "turba" (la esponja de páramo) en beneficio de explotaciones agrícolas y agroindustriales ubicadas en los vaIles; así como de la transferencia de fertilidad en beneficio de la agricultura de las zonas bajas a través del mecanismo de la venta de estiércol de las distintas variedades de ganado ubicadas en estas zonas, ambas prácticas, desafortunadamente, son todavía comunes entre algunos productores de la Sierra central.

\subsection{Los sistemas de pastoreo de altura}

El pastoreo altoandino conforma un sistema de producción en el que interactúa la comunidad biótica con el medio ambiente, en donde los pastizales son el recurso energético vegetal primario que los rebaños transforman en energía animal. La dinámica energética está compuesta por los diversos flujos de nutrición o energía, que se complementa con la energía que ingresa del exterior, desde otros sistemas como el agrícola-. La adaptación cultural al ecosistema, es el proceso por el cual el hombre hace uso efectivo del potencial energético del medio con propósitos productivos (veáse Flores, 1983, p. 17).

Los productores primarios del páramo, o sea la vegetación formada por pastos naturales, tiene gran importancia, porque es la fuente energética que alimenta a los mamíferos que se constituyen en sus principales consumidores primarios, y la transforman en carne, fibra, capacidad de carga y transporte, combustible y otros beneficios adicionales, que permiten la vida humana en las grandes alturas.

En el país, el sistema de pastoreo de altura se ha realizado en el páramo, sin ocuparlo en su totalidad, sino entre las cotas 3.700 en la cordillera Occidental y $3.500 \mathrm{msnm}$ en la Oriental, hasta los $4.300 \mathrm{msnm}$. Se caracteriza por su utilización permanente, en base a las pasturas naturales o artificiales, en Pilahuín, provincia de Tungurahua, se tienen pastos artificiales a $3.800 \mathrm{msnm}$ -

Otros aspectos que caracterizan este tipo de economías son la tenencia de la tierra y animales; y la organización para el trabajo.

La tenencia de la tierra es un arreglo que combina propiedad individual de pequeñas parcelas y propiedad colectiva de extensas áreas de pajonal. El caso de propiedad exclusivamente colectiva se presenta (Hess, p. 76) en los siguientes casos: en áreas de baja presión demográfica; en organizaciones con una larga tradición ganadera sobre la tierra comunal; o en tierras poco aptas para cultivos y sin riego (es decir cuando la presión demográfica es baja y la posibilidad de elevar la productividad del suelo es nula). Se presentan excepciones, como en Salamalag Chico (provincia de Cotopaxi) que mantiene la tenencia colectiva del páramo a pesar de la alta presión demográfica que soporta el área. En cuanto a la propiedad colectiva de animales, se da en el caso de bovinos y ovinos mejorados, que representan una elevada inversión y una potencial rentabilidad mercantil. 
La organización de la fuerza de trabajo es función de la forma de la propiedad predial y de los animales. Se presenta una organización familiar en el caso de tenencias privadas de tierra y animales, en donde el cuidado de hatos colectivos y su pastoreo requiere una división social del trabajo. Predomina la tenencia colectiva de la tierra para usos en pastoreo con animales de renta.

Las especies pecuarias utilizadas en el sistema de pastoreo del páramo usualmente han sido los ovinos -tendencia que al parecer subsiste como una tradición heredada de la época colonial, actividad de gran importancia para los obrajes (CESA, 1983, p. 108)-. En la actualidad, a pesar de su escasa adaptación, por factores que se analizan adelante, se han introducido al sistema bovinos, equinos, caprinos, y hasta porcinos.

En lo que concierne a la productividad del ecosistema, las condiciones de altura y baja temperatura determinan que los procesos vitales -como los ciclos de la materia orgánica, desarrollo de la vegetación, crecimiento y rebrote de los pastos, etc. sean lentos, lo cual incide en la baja fertilidad del ecosistema; así, la capacidad receptiva del pajonal es un bovino de 500 $\mathrm{kg} / 7$ ha que llevado a unidad de superficie equivale a 0.14 unidades bovinas/ha (MAG ORSTOM, 1977, p. 8).

Para elevar la fertilidad del páramo, e incrementar la productividad de los pastos, los criadores en las alturas, generalmente implementan un sistema de quemas del pajonal en la finalidad de "fertilizar"el suelo (en base al potasio de la ceniza) y lograr el rebrote de paja tierna, de mejor calidad y palatabilidad.
No obstante, los efectos e impactos que esta práctica ejerce sobre el ecosistema son múltiples y su reacción es en cadena, así:

- Se pierde el valor biológico y la actividad de los microorganismos del suelo;

- Libera en forma masiva los nutrientes acumulados en la vegetación haciendo aprovechable sólo una pequeña fracción de ellos en el proceso de regeneración de la vegetación; acelera la mineralización de la materia orgánica, que si bien ayuda al rebrote de los pastos y les da mayor suculencia, provocan, de otra parte, la lixiviación de estos minerales, al comenzar las lluvias; y altera los ciclos de nutrientes que mantienen el equilibrio global del ecosistema;

- Destruye la plantas leñosas lo cual da lugar a la expansión de plantas de crecimiento rápido, como la paja, generando un fuerte impacto sobre muchas de las especies vegetales capaces de retener agua... Áreas sometidas a quemas periódicas han quedado con la fisonomía de un simple pajonal, eliminándose muchos de los microhábitats de la fauna y sus fuentes de alimentación;

- Desvía y detiene los procesos naturales de sucesión vegetal. En lugares de pendiente donde el pastoreo es intensivo, se pierde sobre el $50 \%$ de la cobertura vegetal, que no podrá recuperar su estado natural. La sucesión vegetal se desvía a especies demasiado frágiles por efectos de la erosión y la pérdida del banco de semilla; 
- La pérdida de la cobertura vegetal también afecta los sitios de refugio, nidación y alimentación de la fauna silvestre, e induce a cambios en la estructura poblacional;

- El fuego sobre la fauna, como efecto directo ocasiona su muerte; indirectamente, afecta el clima y microclima local, la estructura de la vegetación y las fuentes de sus alimentos.

Otra forma de incrementar la productividad del páramo es la siembra de pastos artificiales. El pasto mejorado tiene un valor nutritivo mayor al de la paja, pero necesita agua suficiente lo cual implica instalar sistemas de riego. Pero también el pasto mejorado se torna menos productivo con la altitud y tiene una menor capacidad de resistencia al pisoteo, lo cual provoca erosión.

Este sistema de producción, en general, tiene un alto costo económico, por su baja productividad, y un alto costo ecológico, por el deterioro del suelo en laderas donde la erosión del agua y el viento es fuerte (Vargas y Rivera, 1991, p. 46).

\subsection{La estructura agraria y su influencia en los sistemas de pastoreo de altura}

En el proceso o período de la conquista las comunas campesinas fueron obligadas a abandonar los valles -tierras fértilesorganizando su vida en reducciones ecológicas de altura o en tierras pobres donde desarrollan un proceso de aprendizaje y adaptación con la naturaleza, en ocasiones mediante una simbiosis entre agricultura y ganadería menor, caracterizada por ovinos y auquénidos (CESA, 1983, p. 72). Esta coyuntura ubica a estas comunidades en los páramos, en las partes más altas de las haciendas, en zonas límite de "Frontera Agrícola" por su altitud marginal para la producción de cultivos -debido a los riesgos de heladas, bajas temperaturas, etc.-, con suelos de menor productividad por su topografía quebrada, y consecuentemente de baja rentabilidad.

Esto da lugar a una estructura agraria concentrada de tipo latifundario, especialmente en la Sierra, que como se señaló, llevó en los 60 y 70 a la implementación de un proceso de Reforma Agraria. ${ }^{3}$ Los objetivos de esta política fueron la formación de una amplia base colectiva y social de la tierra adjudicada en poder de los campesinos.

La actual utilización del suelo del páramo y la estructura de tenencia de la tierra, se relaciona directamente con estos procesos. Así se encuentra, en la zona Occidental -que soporta una alta densidad poblacional y presenta limitaciones topográficas- un predominio del sistema de minifundios y una ganadería ovina. En cambio la zona Central menos poblada y de mejor topografía- se ubica un mayor número de haciendas y organizaciones colectivas de ganadería bovina; en la hacienda tradicionalmente se ha utilizado el pajonal como un recurso de uso extensivo para la cría de ganado de lidia o temporalmente para la ceba de bovinos.

Esta situación, se ha profundizado. Por una parte, el incremento poblacional -entre 1962 y 2010, la población del país se multiplicó por 3.2, y en números absolutos se incrementó de 4.5 a 14.5 millones (INEC)- ha

\footnotetext{
${ }^{3}$ Sobre los antecedentes y efectos del proceso de RA se dispone de abundante literatura; se puede revisar MAG, JUNAPLA, IERAC, 1986; Sepúlveda, 1982; Zevallos, 1990; Haney y Haney, 1990; Thurner, 1990
} 
acentuado la presión sobre la tierra, con efectos hacia el aumento de la propiedad minifundiaria, debido a su parcelación; al mismo tiempo ha complicado la delimitación y legalización del recurso predial, lo cual -en caso de propuestas individuales o colectivas de proyectos de desarrollo- significa falta de garantías reales, y dificultad por acceder al sistema financiero formal.

Esto se expresa, sea en el creciente número de familias jóvenes sin tierra o con parcelas muy pequeñas, que emigran temporal o definitivamente, como una respuesta a la escasez del recurso; o en las tendencias de la producción agropecuaria en los páramos del país con el ascenso altitudinal de la frontera agrícola, y el desarrollo de una ganadería intensiva en las cotas bajas del páramo.

La coyuntura, al mismo tiempo, ha logrado desarticular las bases de la propuesta para una economía colectiva y ha dado lugar a economías campesinas familiares individuales.

\section{Situación actual del páramo}

De la caracterización anterior se encuentra una problemática que se caracteriza por lo siguiente:

- Las zonas de vegetación natural por arriba de los 3.200 m.s.n.m. en las sierras andinas están en un equilibrio morfo-dinámico frágil. Este equilibrio es disturbado en muchas ocasiones por la agricultura

- La línea de contacto entre el páramo y el piso de la agricultura de altura no está definitivamente fijada: es una frontera móvil actualmente en expansión. La necesidad de extender la zona de cultivo, provoca al momento una gran expansión de los cultivos de altu- ra en perjuicio del páramo. El fenómeno no está desprovisto de peligro.

- Todas las prácticas agrícolas (cultivos, ganadería y también forestación) tienen como consecuencia que la capa de vegetación desaparece durante un determinado periodo: por ejemplo, en el caso de cultivos el suelo es arado antes de la siembra y en el caso de ganadería la quema es una práctica común. La desaparición de la vegetación protectora causa una exposición del suelo al aire y aumenta la evaporación en el suelo superficial. Cuando esto ocurre, se tiende a interrumpir el efecto mutuo entre agua y materia orgánica: por menos humedad hay un aumento de la descomposición que resulta en menos materia orgánica en el suelo y así, a su vez, en una menor capacidad de retención de agua. Este efecto es muy significativo, porque los suelos volcánicos poco desarrollados (que se encuentra en la mayoría de los páramos) se secan irreversiblemente y no recuperan su morfología original cuando se vuelven a humedecer.

- La ausencia de una cobertura protectora del suelo durante una parte del año, las pendientes fuertes y otros aspectos de las prácticas agrícolas, por ejemplo, labranza en la dirección de la pendiente, han ocasionado la erosión acelerada en áreas con agricultura.

- El páramo está subutilizado y mal aprovechado, especialmente con la ganadería bovina. Esta problemática aborda los niveles de mantener una base genética mestiza de bajos rendimientos productivos, su manejo extensivo -a causa de las condiciones ecológicas, no será posible un manejo 
de rejos de gran rendimiento en leche y carne- y el fenotipo del animal -de gran peso corporal y forma de la pezuña- que causa daños irreversibles en el suelo del ecosistema. La cría de ovinos, de la misma manera, se realiza en base a razas mestizas, en gran parte de bajo rendimiento. En consecuencia, el poblador del páramo, eminentemente pastor, vive en condiciones de extrema pobreza, debido a que las explotaciones con este tipo de animales, en la mayoría de los casos no son rentables, ni sustentables, más aún, son perjudiciales para este importante y frágil ecosistema. Por otra parte, el pastoreo en los páramos disminuye la porosidad de los suelos por compactación, aumentando el riesgo de escorrentía superficial y erosión asociada.

- En el plano silvícola, a primera vista parecería que la implantación de arboles en el páramo, que hasta ahora son casi únicamente exóticos, favorece la estabilidad del ecosistema: al crear más biomasa y por ende aumentar la cobertura vegetal al incorporar material orgánico al suelo. Pero esta aproximación no es tan cierta. Primero, durante la implantación se quita (parte de) la vegetación existente y se disturba el suelo. Pero más importantes son los efectos durante el crecimiento de la plantación, especialmente especies como el pino, consumen mucha agua, disminuyen el rendimiento hídrico y esto ocasiona la desecación del suelo. En estas condiciones se aceleran los procesos de descomposición de la materia orgánica misma que no es compensada por nuevos aportes, porque la hojarasca de pino es muy uniforme y resistente a la descomposición microbiana, que trae como efecto un suelo con baja capa superficial orgánica y con menor humedad.

Lo anteriormente enunciado conforma una situación en la cual todo el potencial que encierra el ecosistema se encuentre amenazado por el mal manejo de sus recursos, la presión de los actores sociales minifundistas pauperizados, la descoordinación interinstitucional, la carencia de planes y políticas para su manejo y la incipiente organización social encaminada a lograr el desarrollo eficiente y sustentable del páramo, por lo que es necesario proponer nuevas alternativas tendientes al manejo técnico, económico, social y ambiental del ecosistema.

\section{Importancia del páramo}

La importancia del páramo se la puede apreciar en las funciones que cumple mismas que se catalogan desde diversas perspectivas:

- Los páramos tienen un importante valor científico y ecológico por su flora, avifauna endémica y su paisaje único, es decir tiene una función ecológica.

- Desempeñan un importante rol en la producción agrícola, pecuaria y forestal, lo cual representa una función económica.

- Son fundamentales para la regulación de la hidrología regional y constituyen la fuente de agua potable para consumo humano de la parte Norte de los Andes, cumpliendo de esta manera una función hidrológica, como "fabricas" de agua, "esponjas" para su al- 
macenamiento o "cuna" del sistema hídrico de los neotrópicos.

- El carácter histórico del uso y ocupación del suelo en el país, hace que en el páramo en la actualidad los actores que usufructúan este espacio geográfico estén polarizados entre grandes y pequeños propietarios, generándose un uso extensivo de los recursos con subutilización de sus potencialidades en las primeras y un uso intensivo con sobreutilización de la capacidades que ofrece el ecosistema en las segundas. En conjunto, el páramo desde esta perspectiva cumple una función social.

- Este importante espacio hasta la actualidad no ha sido valorado en las dimensiones enunciadas por ninguno de los actores de los cuales depende su aprovechamiento productivo y conservación, lo cual ha generado un manejo sin planificación y normativas, especialmente por parte del Estado, que han llevado a su deterioro y la tendencia hace prever fuertes impactos ambientales, sociales y económicos tanto a su interior como al contexto global nacional. Esta por tanto constituye una función institucional, sin gestión eficaz y eficiente.

\section{Iniciativas de manejo y conservación de páramos}

Algunas de las iniciativas de manejo y conservación de páramos desarrolladas con más énfasis en el país en los últimos 20 años, son las siguientes:

- Elaboración de planes de manejo y conservación de páramos.
- Acuerdos entre el Estado, comunidades y, particulares para la conservación de áreas naturales en zonas de altura, así como de sus zonas de amortiguamiento.

- Acuerdos para el manejo y conservación entre comunidades y particulares.

- Desarrollo de proyectos para el aprovechamiento sustentable del páramo. Aprovechamiento eco turístico del páramo.

Las estrategias señaladas no son disyuntivas, sino al contrario, son generalmente complementarias.

Por lo demás, como se plantea en el Séptimo Foro de los Recursos Hídricos, un elemento central en todas las estrategias indicadas (y en otras), es el de la participación comunitaria; máxime cuando además de las comunidades directamente relacionadas con el páramo, se involucra la organización de segundo grado, la junta parroquial, las juntas de agua, etc. En este caso, al hacer referencia a la participación ésta es entendida como un proceso en el que se van formando capacidades reales, para que los involucrados puedan tomar decisiones cada vez más conscientes entorno a la problemática que les rodea y se comprometen a ser parte de su transformación. Es en el propio proceso en donde se va profundizando la participación. Esto significa realizar acciones de motivación, sensibilización, capacitación, demostración, intercambio de experiencias, entre otras (Zambrano, 2003). 


\section{Actuación del Estado frente a los pá- ramos}

De manera general, habría que señalar que las lógicas de intervención del Estado respecto a los páramos, se han dado en tres direcciones (no siempre interarticuladas):

directas, fundamentalmente a través de la conformación de reservas ecológicas estatales en zonas con importantes superficies de páramo. ${ }^{4}$ Son: los parques nacionales: Cotopaxi y Sangay; las reservas ecológicas: Cayambe Coca, Antisana, El Angel y Cotacachi Cayapas; la Reserva de Producción Faunística Chimborazo; y las áreas nacionales de recreación: Boliche y Cajas.

b) En políticas enfocadas al tema de los páramos, a través de la generación de incentivos económicos para la conservación y la adopción formal de políticas públicas específicas.

\footnotetext{
${ }^{4}$ No hay duda que la actuación del Estado que más ha contribuido a conservación de los páramos ha sido la conformación de áreas naturales que han abarcado territorialmente importantes superficies de esos ecosistemas de altura; este reconocimiento es necesario, al margen de la necesidad de abrir una discusión en torno a las implicaciones sociales de la forma en cómo se constituyeron esas reservas ecológicas y, cómo se han venido manejando las mismas por parte del Estado.

No debe perderse de vista que al interior de varias de las áreas naturales hay tanto propiedades particulares (haciendas y predios familiares), como también propiedades comunitarias. Al declarar áreas naturales protegidas, el Estado lo ha hecho de modo unilateral, omitiendo las obligadas y necesarias consultas a las comunidades, ya sobre cuestiones relativas a los objetivos de esas declaratorias, a las fronteras de las mismas; ya sobre el reconocimiento a los derechos de propiedad y posesión afincadas por comunidades y particulares; ya sobre las formas de conciliar la condición de áreas naturales con el reconocimiento al hábitat y las prácticas comunitarias en esos espacios, etc.
}

c) En la formulación de políticas agrarias con notable incidencia de los páramos tal es el caso de la legislación de reforma agraria; a lo que habría añadir la influencia (negativa ciertamente) que sobre los páramos tuvo la política orientada a habilitar y estimular la conformación de un mercado de tierras comunitarias a través de la Ley de Desarrollo Agrario del año 94.

\section{Conclusiones}

- El ecosistema páramo es fruto de las transformaciones geológicas del planeta que han ocurrido a lo largo de milenios; pero a la vez de la presencia milenaria de poblaciones y de sus estructuras sociales; por lo tanto, su actual conformación solo puede explicarse a partir de la comprensión de las relaciones, pasadas y presentes, que han establecido las distintas formaciones sociales con la naturaleza.

- El páramo no debe ser considerado únicamente como un ecosistema frágil, atendiendo a su vulnerabilidad y las permanentes amenazas antrópicas, sino que además tiene que considerarse también su carácter estratégico para la naturaleza, la sociedad y la economía nacional, dadas las irremplazables funciones ecológicas, biológicas, hidrológicas, sociales, culturales y económicas que tiene este agro ecosistema.

- $\quad$ Por el significado que pueden llegar a tener en el futuro como fuente de agua, los páramos húmedos deberían ser declarados reservas de la biósfera; y los demás páramos deben ser declarados reservas municipales o provinciales, por 
su importancia para los acueductos locales.

- Los ecosistemas parameros funcionan adecuadamente en condiciones bioclimáticas regulares, que se han establecido a través de muchos años. Sin embargo, las variaciones extremas y los cambios de largo plazo de estas condiciones pueden afectar considerablemente y generar impactos ambientales y socioeconómicos de importancia. En los páramos es obvio que el cambio climático produce, precisamente, alteraciones en el clima que se manifiestan en las variaciones de la temperatura y las precipitaciones; esto a su vez causaría graves transformaciones, por ejemplo, en los suelos y en la biodiversidad y así afectarían a toda la gente que depende de este ecosistema.

- De lo anterior, se desprende que las lógicas e intereses de ocupación de los páramos han sido no solo diversas, sino en muchos casos contradictorias; súmese que los instrumentos normativos utilizados para formalizar esa ocupación responden a enfoques jurídicos harto disímiles; con ello, no hace falta esforzarse mucho para entender que esas distintas modalidades de acceder a la propiedad de los paramos, son a la vez, fuente permanente de tensiones y conflictos, en torno a las lógicas y prácticas de uso del suelo, en torno a los derechos de propiedad, posesión, uso, usufructo, servidumbres, así como en torno a linderos y delimitación.

7. Elementos de una política alternativa para la conservación y aprovechamiento sostenible de los páramos
Se plantean los contenidos de una propuesta alternativa para la conservación y aprovechamiento sostenible de los páramos, que fueron la síntesis del Séptimo Foro de los Recursos Hídricos:

- La obligación de desarrollar, política y normativamente, el reconocimiento constitucional de los derechos de la naturaleza, así como el mandato establecido en el artículo 406 que dispone que el Estado regule la conservación, manejo y uso sustentable, recuperación, y limitaciones de dominio de los ecosistemas frágiles y amenazados como los páramos.

- La necesidad de asumir aquella declaración constitucional de que el páramo es un ecosistema frágil, atendiendo a su vulnerabilidad y las permanentes amenazas antrópicas; pero también, la importancia, desde el punto de vista político y normativo, de reconocer también su carácter estratégico para la naturaleza, la sociedad y la economía nacional, dadas las irremplazables funciones ecológicas, biológicas, hidrológicas, sociales, culturales y económicas que tiene este ecosistema. En ésta perspectiva, resulta importante el reconocimiento que ha realizado el Gobierno Provincial de Tungurahua que declara a los páramos de esa provincia como áreas estratégicas de interés colectivo y político para el desarrollo económico y social de toda la población

- La necesidad de reconocer distintas formas de propiedad y posesión en los páramos: la propiedad estatal, bajo responsabilidad del Ministerio del Ambiente; la propiedad y posesión pública bajo responsabilidad de algu- 
nos municipios o sus empresas comunitarias de agua o, bajo responsabilidad de empresas hidroeléctricas; la propiedad y posesión comunitaria, bajo responsabilidad de comunas, comunidades o, juntas de agua; y, la propiedad y posesiones privadas, bajo responsabilidad de haciendas, empresas o individuos. (La propiedad o posesión de tierras del páramo, genera derechos, pero sobre todo, responsabilidades).

- La necesidad de que las tensiones sociales y conflictos generados en el páramo puedan ser canalizados y tratados institucionalmente, en el marco de disposiciones normativas que orienten su tratamiento y resolución.

- La necesidad de incorporar lineamientos que permitan atenuar el impacto del cambio climático sobre los páramos y otros ecosistemas de altura.

\section{BIBLIOGRAFÍA}

ACOSTA SOLÍS, M. (1984). Los páramos andinos del Ecuador, Quito.

CAÑADAS, L. (1983). El mapa bioclimático y ecológico del Ecuador, Quito, Banco Central.

CESA (1983). "Políticas y economías campesinas en ecosistemas de altura: caso Pilahuín, zona interandina, Ecuador", en CEPAL PNUMA,_Sobrevivencia Campesina en Ecosistemas de Altura. Vol. II: 67-150. Santiago de Chile

CRISSMAN, CH. (2003). La agricultura en los páramos: estrategias para el uso del espacio. Lima, CONDESAN.

FLORES, J. (1983). El ecosistema del pastores andino en las tierras altas de los Andes Centrales, en CEPAL PNUMA, Sobrevivencia Campesina en Ecosistemas de Altura. Vol. II: 3-66. Santiago de Chile

GONDARD, P. y MAZUREK, H. (2001). “30 años de Reforma Agraria y Colonización en el Ecuador", en GONDARD, P y LEÓN, J. (Eds.) Dinámicas territoriales. Estudios de Geografía, No. 10. Quito, IRD, Colegio de Geógrafos del Ecuador, PUCE, Corporación Editora Nacional.

HANEY, E.Y. HANEY, B. (1990). "La transición agraria en la Sierra del Ecuador. Del semifeudalismo al capitalismo en Chimborazo", en Ecuador Debate, Vol. 20:147-182. Quito, CAAP.

HESS, G. (s/f). "Hacia Arriba, Hacia Abajo. Un bosquejo de sistemas de producción en el páramo", en IGM Revista Geográfica. No. 29: 65-81. Quito. 
INEC. Censos de Población 1962 y 2010. Quito.

MAG-JUNAPLA-IERAC (1986) "Conclusiones de la evaluación de la Reforma Agraria”, en Corporación Editora Nacional, Pensamiento agrario ecuatoriano. Quito, Banco Central.

MAG-ORSTOM (1977). Quito.

ECUADOR (2008). Constitución Política del Estado ecuatoriano, Quito.

SEPÚLVEDA, C. (1982). Estructuras agrarias y reproducción campesina. Lecturas sobre transformaciones capitalistas en el agro ecuatoriano. Quito, Universidad Católica-IIE.

THURNER, M. 1990. Disolución de la hacienda. Luchas campesinas y mercado de tierras en la Sierra Central del Ecuador (cantón Colta, provincia de Chimborazo). En, Ecuador Debate. Vol.20: 69-145. Quito, CAAP.

VARGAS, O. y RIVERA, D. (1991). "El páramo, un ecosistema frágil", en Bosques y Desarrollo. No. 2:45-48. Bogotá.

ROMÁN, F., MENA, P., ZAPATA, A. (2013). "Páramos, agua y cambio climático", en ZAMBRANO, C. Agua, Estado y Sociedad. Aportes para políticas públicas. Quito, CAMAREN, pp. 89-140.

ZAMBRANO, C. Agua, Estado y sociedad. Aportes para políticas públicas. Quito, CAMAREN.

ZEVALLOS, J. (1990). "Reforma Agraria y cambio estructural: Ecuador desde 1964", en Ecuador Debate. Vol. 20:23-68. Quito, CAAP. 